Housing and Health among Young First Nations Children Living Off Reserve: Results from the 2006 Aboriginal Children's Survey

Anne Guèvremont, Evelyne Bougie, and Dafna Kohen

Statistics Canada

aboriginal policy studies Vol. 5, no. 2, 2016, pp. 81-98

This article can be found at:

http://ejournals.library.ualberta.ca/index.php/aps/article/view/24313

ISSN: $1923-3299$

Article DOI: http://dx.doi.org/10.5663/aps.v5i2.24313

aboriginal policy studies is an online, peer-reviewed and multidisciplinary journal that publishes original, scholarly, and policy-relevant research on issues relevant to Métis, non-status Indians and urban Aboriginal people in Canada. For more information, please contact us at apsjournal@ualberta.ca or visit our website at www.nativestudies.ualberta.ca/research/aboriginal-policy-studies-aps.

UNIVERSITY OF ALBERTA

FACULTY OF NATIVE STUDIES

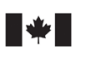
Aboriginal Affairs and
Northern Development Canada Affaires autochtones et Développement du Nord Canada 


\section{Housing and Health among Young First Nations Children Living Off Reserve: Results from the 2006 Aboriginal Children's Survey}

Anne Guèvremont, Evelyne Bougie, and Dafna Kohen ${ }^{1}$

Statistics Canada

Abstract: First Nations children in Canada often experience poorer housing conditions than other Canadian children. This study used the 2006 Aboriginal Children's Survey to examine the relationship between housing and physical and mental health for First Nations preschool-aged children living off-reserve. This study provides evidence that the physical, spatial, and psychological aspects of housing in which young off-reserve First Nations children live are associated with their physical and mental health, even after controlling for family socioeconomic factors, area of residence, and child's age and sex (analyzed with regression models). In particular, homeownership, parental satisfaction with housing, and number of moves per year were all associated with multiple physical and mental health outcomes. Future research is needed to further investigate the mechanisms at play.

First Nations children in Canada often experience worse housing conditions than other Canadians. In 2006, eighteen percent of off-reserve First Nations children under six years old were living in homes requiring major repairs, more than twice as high as the percentage of non-Aboriginal children (eight percent). As well, sixteen percent were living in crowded conditions, compared to seven percent of the non-Aboriginal population (Statistics Canada 2008). First Nations people, living both on and off-reserve, were also less likely to own their own homes and to have trouble finding affordable housing (CMHC 2009, 2011a, 2011b). In addition, First Nations children are often in poorer physical and mental health than other Canadian children (UNICEF 2009; MacMillan et al. 2010; Oliver and Kohen 2012). Early childhood is a particularly important time period to study housing and its association with health, because young children spend the majority of their time indoors (Hofferth and Sandberg 2001) and early effects can have a lasting impact over a child's lifespan (Power and Hertzman 1997). This study aims to examine the relationship between housing characteristics and physical and mental health for First Nations preschool-aged children living off-reserve.

Research frameworks exist to help guide the investigation of the relationships between housing and health (e.g. CMHC 2004). Three dimensions of housing are considered important: material dimensions, spatial dimensions, and psychological dimensions. Material dimensions include physical aspects such as indoor air pollution from molds and

1 Disclaimer: This paper was funded by the Strategic Research Directorate at Indigenous and Northern Affairs Canada (INAC). The views expressed in this document are those of the authors and do not necessarily represent the position of Statistics Canada or INAC.

aboriginal policy studies, vol. 5, no. 2, 2016 
the conditions of the building, such as whether it is in need of major repair or whether there is a smoker in the home. Material dimensions also include financial aspects of housing, such as whether the housing is affordable and also whether is it owned by a member of the household. Second, spatial dimensions include both housing suitability (including crowding) and the surrounding environment, including the neighbourhood. Included in spatial dimensions are how long a child stays in the same residence or how frequently he or she moves. Lastly, psychological dimensions of housing include the sense of control a person feels regarding his or her housing, as well as how satisfied a person is with his or her housing. The psychological dimension of housing is related to the material and spatial dimensions, as homeownership, crowding, and neighbourhood safety can affect a person's sense of control (CMHC 2004).

All of the above aspects of housing have been associated with children's health in the general population (see Hwang et al. 1999; Boyle 2002; Haurin et al. 2002; Moloughney 2004; World Health Organization 2011; Jelleyman and Spencer 2008). In terms of material aspects, people who live in houses that are damp and mouldy, or in houses where people smoke, are more likely to have respiratory conditions (asthma, allergies, bronchitis, etc.) (Hwang et al. 1999; World Health Organization 2011). Some houses may present conditions that could cause injuries, such as loose window screens or poor overall construction (Moloughney 2004). Homeownership has been associated with better general physical and mental health and also with fewer behaviour problems in children (Moloughney 2004; Boyle 2002). As for spatial aspects, people living in crowded homes are more likely to have respiratory conditions; to have infectious diseases (World Health Organization 2011); and to have worse health overall (Evans 2006). Some research has also found that people living in crowded homes have worse mental health, although the evidence is mixed (Hwang et al. 1999). Frequent moves have been associated with behavioural and emotional problems in school age children (Jelleyman and Spencer 2008). Lastly, in terms of psychological aspects, satisfaction with housing conditions has been associated with better general physical and mental health (Moloughney 2004).

Some research on housing and health has been conducted among the First Nations population in Canada. Findlay and Janz (2012) found that off-reserve First Nations children under age six were less likely to be in good health (as reported by parents) if they lived in large households, moved frequently, and had parents who were dissatisfied with their housing conditions, even after adjusting for relevant family socio-demographic factors. As well, in a study conducted with two First Nations communities in Manitoba (Lac Brochet and Valley River), adults living in crowded houses were more likely to report having tuberculosis (Larcombe et al. 2011).

However, relatively little empirical research has examined the relationship between housing characteristics and health outcomes for First Nations children. Examining this relationship is important because First Nations children have been shown to have both poorer housing conditions and poorer health outcomes compared to other children in Canada. This study will report on the housing characteristics of young off-reserve First 
Nations children, as well as examine whether material, spatial, and psychological housing characteristics are associated with physical and mental health outcomes for young First Nations children living off-reserve.

One of the challenges in studying housing and health is figuring out the role of socioeconomic status (SES). This is important because lower SES is associated with poorer health; conditions such as household income (Reading 2009), parental education (Bulkow et al. 2002), and family structure (Kovesi et al. 2007) have all been found to be related to Aboriginal children's health. Not only is lower SES associated with poorer health, but also with poor housing conditions, and poorer housing is in turn also associated with poor health (Hwang et al. 1999; Moloughney 2004). Therefore, this study will also examine whether there is still a relationship between off-reserve First Nations children's health and housing conditions after accounting for family SES.

\section{Methods}

\section{Data Source and Measures}

Data for this study were obtained from the 2006 Aboriginal Children's Survey (ACS). The 2006 ACS is a national survey of Aboriginal children (First Nations living off-reserve, Métis, and Inuit) under six years of age living in urban, rural, and northern locations throughout Canada. Children living on First Nations reserves were not included in the survey. ${ }^{2}$ This study focused on a subset of the survey, off-reserve First Nations children ${ }^{3}$ aged two to five (a total of 3,640 children), who were identified by parents or guardians as First Nations on the 2006 ACS, either as a single identity or in combination with another Aboriginal identity. For the comparison of other socio-demographic characteristics, data for two to five years olds from the 2006/07 National Longitudinal Survey of Children and Youth (NLSCY) was used.

\section{Material Aspects of Housing}

Four material aspects of housing were included, all coded as binary variables. The first three are derived from the 2006 Census: (1) dwelling in need of major repair was based on a single item that asked, "Is this dwelling in need of any repairs? (no, only regular maintenance/ yes, minor repairs/yes, major repairs)"; (2) unaffordable housing was calculated based on reported housing costs that were greater than thirty percent of before-tax household income; and (3) homeownership_-"Is this dwelling owned by you or a member of this household (even if it is still being paid for)?" The fourth material aspect examined was

2 More information about the 2006 ACS can be found in the ACS 2006 Concepts and Methods Guide (Statistics Canada, catalogue no. 89-634).

3 First Nations children are children who were identified by parents or guardians as North American Indian on the 2006 ACS, as a single identity or in combination with another Aboriginal identity. 
based on the survey question regarding the presence of a (4) regular smoker in the house"Including both household members and regular visitors, does anyone smoke inside your home every day or almost every day (yes/no)?"

\section{Spatial Aspects of Housing}

One spatial aspect of housing was derived from the 2006 Census: (1) crowding was defined as more than one person per room. Another was drawn from the survey, that regarding (2) one or more moves per year- "How many times in his/her life has (child) moved, that is changed his/her usual place of residence?" This was divided by the child's age, and then categorized as either more than or less than one move per year. Both were coded as binary variables.

\section{Psychological Aspects of Housing}

One psychological aspect of housing was based on the survey category (1) parental satisfaction with housing conditions-"How would you rate your feelings about your housing conditions (Very satisfied / Satisfied vs. Dissatisfied / Very dissatisfied)?”

\section{Family and Child Socio-demographic Conditions}

Six family and child socio-demographic conditions associated with both housing conditions and child health were included: parents' highest level of education (completed high school vs. not completed high school); household income (continuous variable, adjusted for household size); single-parent family (compared to two-parent family); area of residence (urban area vs. outside urban area); and child's sex and age.

\section{Health Outcomes}

Physical child health outcomes included parent-rated child health status (excellent/very good vs. good/fair/poor), two or more ear infections in past twelve months (vs. less than two), activity limitation (yes/no), presence of two or more chronic conditions (yes/no), chronic respiratory conditions (including allergies, asthma, and/or bronchitis), and serious injury in the past year. These variables were used as binary outcomes.

Mental health/behavioural outcomes were assessed with the Strengths and Difficulties Questionnaire (SDQ; Goodman 1997, 2001), previously validated for the ACS sample (Oliver et al. 2009). Each item on the questionnaire is rated by the child's parent or guardian using the responses "not true" (scored as 0), "somewhat true" (scored as 1) or "certainly true" (scored as 2). Items are summed to create sub-scales, which are used as continuous outcomes. We used the four sub-scales suggested by Oliver et al., which are as follows:

Prosocial Behaviour: this sub-scale is composed of ten items including questions such as "Is he/she ... considerate of other peoples' feelings?" And "Is he/she ... helpful if someone is hurt, upset, or feeling ill?" 
Emotional Symptoms: this subscale is composed of five items including questions such as "Is he/she ... often unhappy, depressed, or tearful?" And "Is he/she nervous or clingy in new situations, easily loses confidence?"

Hyperactivity/Inattention: this subscale is composed of three items including questions such as "Is he/she ... constantly fidgeting or squirming?" And "Is he/she ... restless, overactive, cannot stay still for long?"

Conduct Problems: this final subscale is composed of four items including questions such as, "[Does] he/she ... often [fight] with other children or [bully] them?" And "Is he/she ... often argumentative with adults?"

\section{Analyses}

Descriptive analyses for housing and family socio-demographic characteristics were examined for off-reserve First Nations and non-Aboriginal children two to five years old. Regression analyses were conducted separately for each child's physical health outcomes (parent-rated child health, two or more ear infections in past 12 months, activity limitation, presence of two or more chronic conditions, chronic respiratory conditions, serious injury in last year) and mental health outcomes (prosocial behaviour, hyperactivity-inattention, emotional symptoms, and conduct problems). Five models were examined: Model 1 included the material aspects of housing (house in need of major repair, unaffordable, homeownership status, and regular smoker in the home); Model 2 examined the spatial aspects of housing (crowded household, one or more moves per year); Model 3 examined the psychological aspects of housing (parental satisfaction with housing conditions); Model 4 included all aspects of housing examined in the previous three models; and Model 5 included all housing factors along with socio-demographic variables to examine and assess the association of housing conditions with child health over and above family-level SES characteristics. Analyses were based on survey data weighted to be representative of the 2006 Census counts of children two to five years old in Canada. The bootstrap method was used to account for the complex sampling design used by the survey. All analyses were conducted using SAS 9.2.

To check for multicollinearity, the correlations between the housing and sociodemographic variables were examined, as were the tolerance and variance inflation for each variable (see Appendix). Household income was correlated with household ownership $(\mathrm{r}=0.53)$, unaffordable housing $(\mathrm{r}=0.54)$, and living in a single-parent family $(\mathrm{r}=0.36)$. All other correlations had Pearson's correlation co-efficient values of less than 0.3 . Due to the somewhat high correlations of household income with homeownership, affordability, and single-parent families, models were run with and without household income included, with similar results (which are available upon request). All values of tolerance were above 0.67 , and all values of variance inflation were below 1.5, indicating that it is appropriate to include all variables in the model and that multicollinearity is minimal (Stevens 2002; Tabachnick and Fidell 2001). 
TABLE 1: Housing conditions and selected characteristics of First Nations children living off reserve and non-Aboriginal children, ages two to five, Canada, 2006

\begin{tabular}{|c|c|c|c|}
\hline & $\begin{array}{l}\text { First Nations } \\
\text { children aged } \\
\text { two to five living } \\
\text { off-reserve, } \\
2006 \text { ACS }\end{array}$ & $\begin{array}{l}\text { Non-Aboriginal } \\
\text { children aged } \\
\text { two to five, } \\
2006 \text { Census }\end{array}$ & $\begin{array}{c}\text { Non- } \\
\text { Aboriginal children } \\
\text { aged } \\
\text { two to five, } \\
2006 / 07 \mathrm{NLSCY}\end{array}$ \\
\hline $\begin{array}{l}\text { Crowded household (more than one } \\
\text { person per room) }\end{array}$ & $\%$ & $\%$ & $\%$ \\
\hline Yes & 10 & 7 & na \\
\hline No & 90 & 93 & na \\
\hline Housing in need of major repair & $\%$ & $\%$ & $\%$ \\
\hline Yes & 17 & 8 & na \\
\hline No & 83 & 92 & na \\
\hline $\begin{array}{l}\text { Housing costs more than } 30 \% \text { of } \\
\text { household income }\end{array}$ & $\%$ & $\%$ & $\%$ \\
\hline Yes & 33 & 20 & na \\
\hline No & 67 & 78 & na \\
\hline Household tenure: Owned & $\%$ & $\%$ & $\%$ \\
\hline Yes & 39 & 74 & na \\
\hline No & 61 & 26 & na \\
\hline One or more moves per year of age & $\%$ & $\%$ & $\%$ \\
\hline Yes & 10 & na & na \\
\hline No & 90 & na & na \\
\hline $\begin{array}{l}\text { Parent very satisfied or satisfied } \\
\text { with housing conditions }\end{array}$ & $\%$ & $\%$ & $\%$ \\
\hline Yes & 84 & na & na \\
\hline No & 16 & na & na \\
\hline $\begin{array}{l}\text { Does anyone smoke inside your } \\
\text { home every day or almost every day }\end{array}$ & $\%$ & $\%$ & $\%$ \\
\hline Yes & 20 & na & na \\
\hline No & 80 & na & na \\
\hline $\begin{array}{l}\text { Parent/guardian highest level of } \\
\text { education }\end{array}$ & $\%$ & $\%$ & $\%$ \\
\hline Not completed high school & 31 & na & 7 \\
\hline Completed high school & 69 & na & 93 \\
\hline Average household income & $\$$ & $\$$ & $\$$ \\
\hline & 49,717 & na & 79,949 \\
\hline Single-parent family & $\%$ & $\%$ & $\%$ \\
\hline Yes & 40 & 85 & 87 \\
\hline No & 60 & 15 & 13 \\
\hline Area of residence & $\%$ & $\%$ & $\%$ \\
\hline Inside urban area & 78 & na & 88 \\
\hline Outside urban area & 22 & na & 12 \\
\hline Child's sex & $\%$ & $\%$ & $\%$ \\
\hline Female & 49 & na & na \\
\hline Male & 51 & na & na \\
\hline \multirow[t]{2}{*}{ Child's age in years } & Mean & Mean & Mean \\
\hline & 4.0 & na & na \\
\hline
\end{tabular}

Notes: All coefficients of variation for ACS data were less than 16.6; na=not applicable.

Sources: 2006 Aboriginal Children's Survey; 2006 Census of Population; 2006/07 National

Longitudinal Survey of Children and Youth. 


\section{Results}

Off-reserve First Nations preschool-aged children in Canada lived in different housing conditions from the non-Aboriginal population of preschool-aged children in Canada. About ten percent of First Nations children living off-reserve lived in a house with more than one person per room, compared to seven percent of their non-Aboriginal counterparts. As well, seventeen percent of off-reserve First Nations preschool-aged children lived in housing in need of major repair (compared to eight percent of non-Aboriginal children), and thirty-three percent lived in unaffordable housing (vs. twenty percent of nonAboriginal children). In addition, ten percent of off-reserve First Nations preschool-aged children had moved once or more per year since birth, sixteen percent had a parent who was not satisfied with the family's housing conditions, and twenty percent lived in a home in which someone smoked every day or almost every day; comparable numbers for the non-Aboriginal population for these three variables are not available (Table 1).

\section{Material Aspects of Housing}

Dwelling in need of major repair. Living in a house in need of major repair was not significantly associated with any of the physical (Table 2) or mental (Table 3) health outcomes included in this study, either before or after controlling for socioeconomic factors.

Tobacco smoke exposure. Having a regular smoker in the home was not associated with any physical health outcomes for First Nations children living off-reserve. However, off-reserve First Nations children living in a household with a regular smoker had higher conduct problems scores than off-reserve First Nations children not living in a household with a regular smoker. This relationship was maintained over and above SES.

Unaffordable housing. Off-reserve First Nations children who lived in unaffordable housing (total costs of rent or mortgage greater than thirty percent of before-tax household income) were more likely to have a physical activity limitation and also more likely to have two or more chronic conditions. After controlling for SES and other housing conditions, unaffordable housing was no longer associated with two or more chronic conditions, but the relationship between unaffordable housing and having a physical activity limitation remained.

Homeownership. Off-reserve First Nations children who lived in an owneroccupied dwelling were less likely to have been seriously injured in the past year and also more likely to be rated as being in very good or excellent health. Homeownership was also associated with higher prosocial behaviour, lower inattention-hyperactivity, fewer emotional symptoms, and lower conduct-problem scores. When socioeconomic conditions were added to the model, homeownership 
was not associated with inattention-hyperactivity, prosocial behaviour, or being in excellent or very good health. However, the relationship among homeownership and injuries, emotional symptoms, and conduct problem scores remained, suggesting that these relationships were significant over and above the effects of socioeconomic factors.

\section{Spatial Aspects of Housing}

Crowding. Before controlling for other variables, results indicated that children who lived in crowded housing conditions (more than one person per room) were less likely to be rated as being in very good or excellent health. They also had lower scores for prosocial behaviour and higher scores for conduct problems. However, after other housing conditions and/or socio-demographic variables were included in the model, crowding was no longer significantly associated with any of the outcomes included in this study.

Residential mobility. Off-reserve First Nations children who moved frequently (one or more moves per year of age) were less likely to be in excellent or very good health, more likely to have a physical activity limitation, more likely to have two or more chronic conditions, and more likely to have a chronic respiratory condition. Their counterparts who moved frequently also had lower scores for prosocial behaviour and higher scores for hyperactivity-inattention, emotional symptoms, and conduct problems. The association between residential mobility and prosocial behaviour was no longer significant after parental education was included in the model, but all of the other associations with residential mobility remained after controlling for socioeconomic factors, suggesting that most of the associations between residential mobility and children's health were not explained solely by socioeconomic differences.

Psychological Aspects of Housing

Parental satisfaction with housing conditions. Off-reserve First Nations children who had parents who were satisfied with their housing conditions were more likely to be in excellent or very good health and less likely to have a physical activity limitation. They also had higher prosocial behaviour scores, lower inattentionhyperactivity scores, fewer emotional symptoms, and lower conduct-problem scores compared to off-reserve First Nations children whose parents were not satisfied with their housing conditions. The relationship between housing satisfaction and inattention-hyperactivity was no longer significant after controlling for sociodemographic variables, but all of the other associations remained after controlling for family socioeconomic factors. 


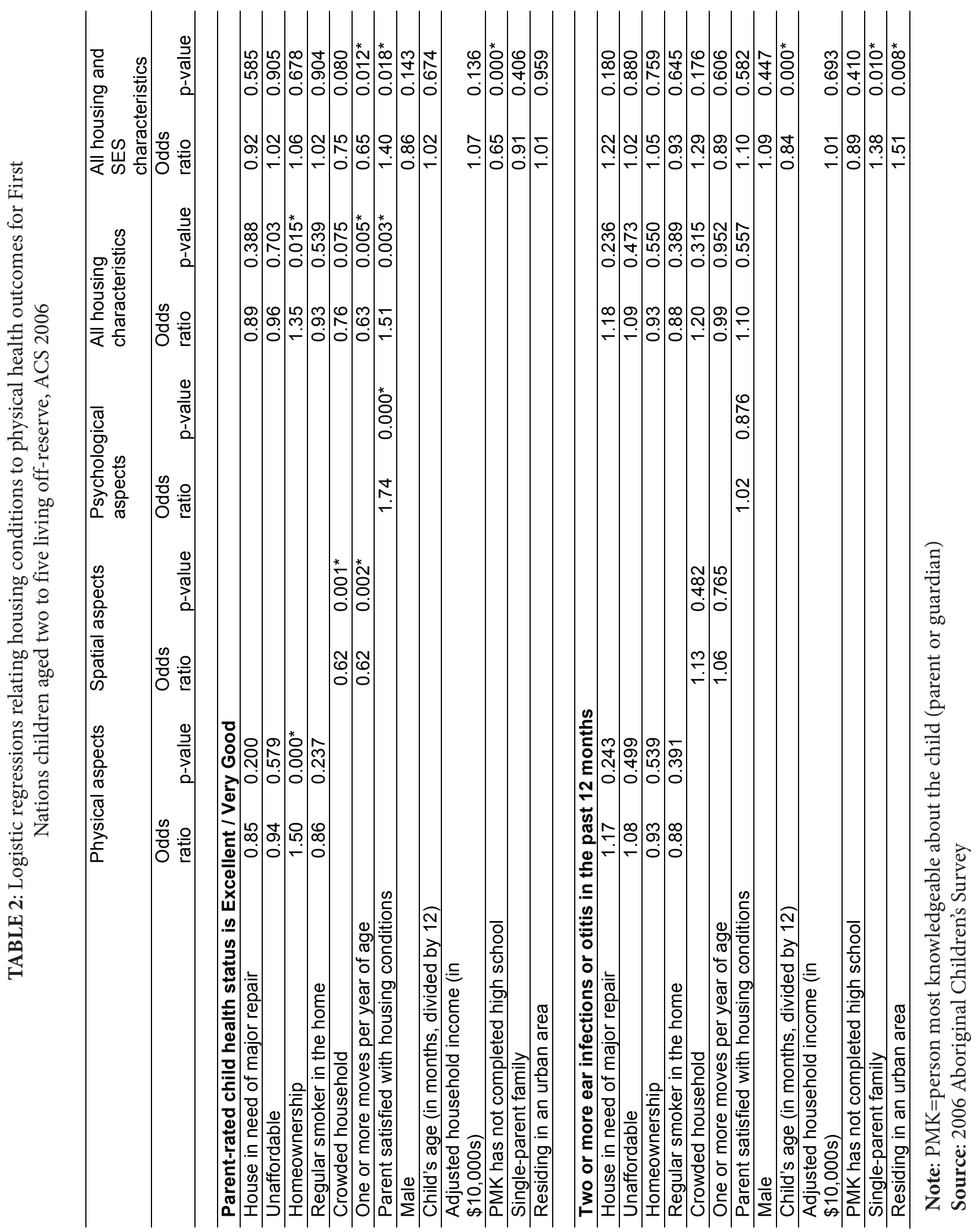




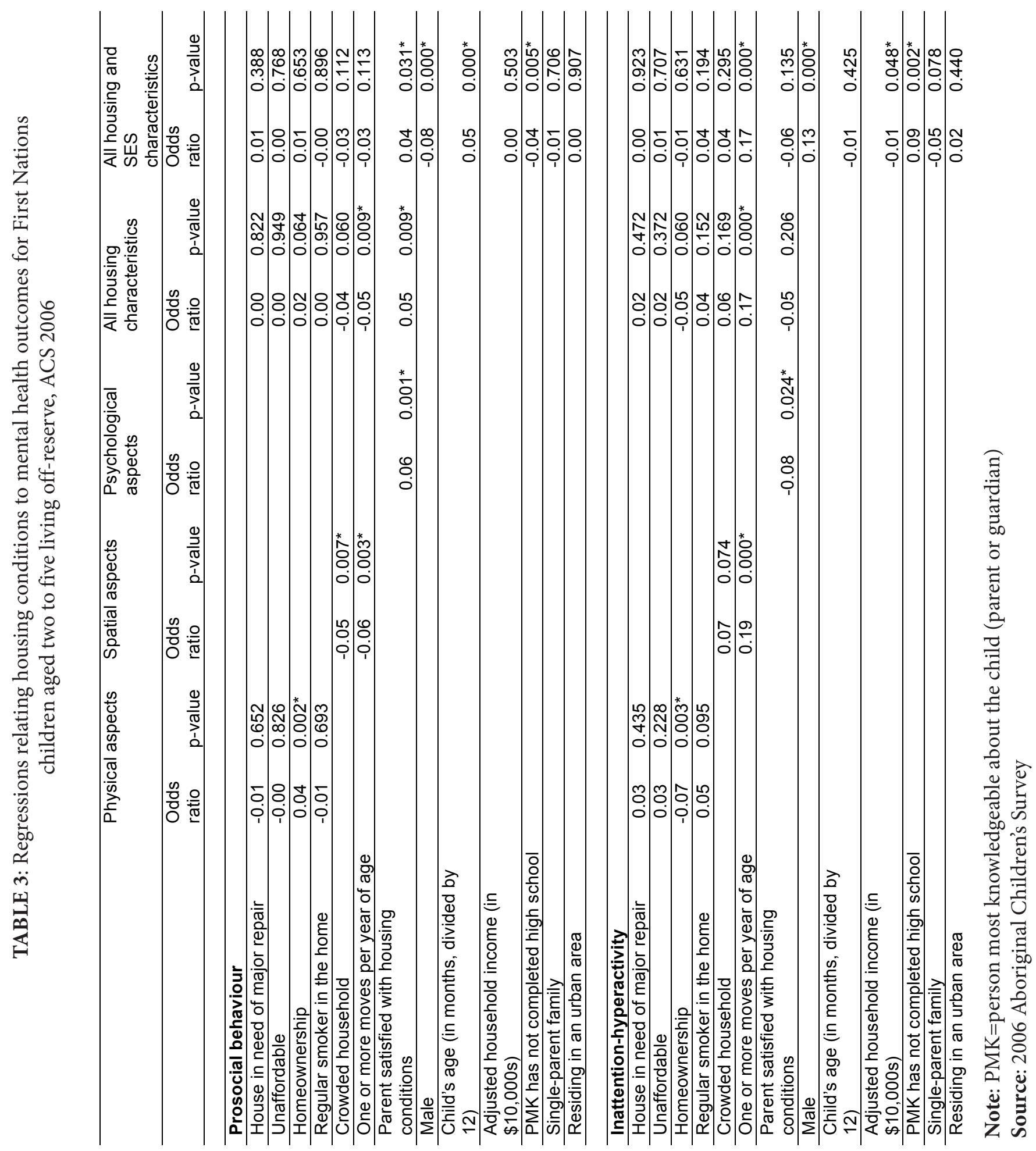




\section{Discussion}

This study provides support for the assertion that the material, spatial, and psychological aspects of housing in which young off-reserve First Nations children live are associated with their physical and mental health, even after controlling for family socioeconomic factors, area of residence, and the child's age and sex. In particular, homeownership, parental satisfaction with housing, and number of moves per year were all associated with multiple physical and mental health outcomes.

For First Nations children living off-reserve, three of the material housing characteristics examined (affordability, homeownership, and having a regular smoker in the home) were associated with a child's physical and/or mental health, whereas one such characteristic (home in need of major repair) was not associated with physical and mental health. In particular, homeownership was associated with multiple physical and mental health outcomes over and above family SES (household income adjusted for household size, parental education, single-parent family, and urban vs. rural area of residence). Specifically, children who lived in an owner-occupied dwelling were less likely to have been seriously injured in the past year. This is consistent with research that suggests that owner-occupied dwellings may contain fewer hazards (Boyle 2002). Homeownership was also associated with fewer emotional symptoms and lower conduct-problem scores. Other research has found that owner-occupied dwellings are located in "healthier" neighbourhoods that may be associated with protective factors-for example, families moving less frequently and neighbours knowing each other, with an expected positive effect on child behaviour (Boyle 2002; Kohen et al. 2008). While beyond the scope of the present study, these additional factors would be interesting to investigate.

Another measure of a material aspect of housing was affordability. Over and above family SES, off-reserve First Nations children who lived in unaffordable housing (total costs of rent or mortgage equalling more than a third of before-tax household income) were more likely to have a physical activity limitation. However, it is not possible to determine the direction of the effect of this relationship. Some families, for instance, may need to live in a home with higher housing costs in order to accommodate children's activity limitations (Hwang et al. 1999); for example, some may require a home close to health services or with different physical features such as ramps or wider doorways. Families with a child with an activity limitation may also have less disposable income, since both parents are less likely to be employed full-time compared to families with children with no such limitations (Burton et al. 2007).

Off-reserve First Nations children living in a household with a regular smoker had higher conduct-problem scores. This relationship was maintained over and above SES. Other studies found that children with mothers who smoked had more behavioural problems during childhood (Weitzman et al. 1992; Hofhuis et al. 2003; Hwang et al. 2012). The present study did not find an association between the presence of a regular smoker in the home and the physical health of off-reserve First Nations children. Some researchers have found a relationship between smoking and Aboriginal child health (Gao et al. 2008), 
but others have not found such a link (Findlay and Janz 2012). However, these studies measured smoking behaviours in different ways and examined different health outcomes. Gao et al. (2008) found that mothers' daily smoking was associated with asthma-like symptoms in Aboriginal children, whereas Findlay and Janz (2012) found no negative association between living in a household with a regular smoker and being in very good or excellent health in off-reserve First Nations and Métis children. Mothers' daily smoking may be associated with asthma because it is associated with smoking during pregnancy, which has been associated with childhood asthma (Jaakkola and Gissler, 2004). Unfortunately, only one question on tobacco smoke exposure was asked in the 2006 ACS, and precludes any further analysis. Future research could examine the effect of number of smokers in a household or whether a child has been exposed to second-hand smoke outside of the home. However, the estimate of twenty percent of young off-reserve First Nations children having a regular smoker in the home is in line with previous research, which reported that fifteen percent of off-reserve First Nations adults (aged twelve and older) were exposed to second-hand smoke in the home (Gionet and Roshanafshar 2013).

After controlling for socioeconomic factors, results indicated that living in a house in need of major repair was not significantly associated with any of the health outcomes included in this study. Perhaps a more detailed measure would have yielded significant findings; it would be useful for future research to know the nature of the needed repairs to evaluate whether a relationship with health outcomes should indeed be expected. For example, some repairs such as leaking roofs or water in the basement may affect indoor air quality, which would be expected to have an effect on a child's physical health.

In terms of the spatial aspects of housing, residential mobility (having one or more moves per year of age) was associated with multiple physical and mental health outcomes for First Nations children living off-reserve, whereas crowding was not associated with any outcomes after controlling for SES and other housing characteristics. Other research has found a link between residential mobility and behavioural and emotional problems in school-age children (Jelleyman and Spencer 2008), and frequent moves have been said to be a marker for a variety of family changes such as divorce and job change which, in turn, are associated with child outcomes (Dong et al. 2005). People move for a variety of reasons: family, employment, better housing (CMHC 2002). ${ }^{4}$ Unfortunately, the reasons for moving were not assessed in the 2006 ACS. Further investigation of the relationship between residential mobility and child health among off-reserve First Nations children is an important area for future research.

Although crowding and housing conditions have been associated with child health in previous studies (World Health Organization 2011; Evans 2006), we found no association between crowding and child health after controlling for SES and/or other housing

4 Data from the 2006 Aboriginal Peoples Survey reveal that among adults living in households with children aged less than five years, the main reasons for moving were "family reasons" (thirty-seven percent), followed by "work / find a job" (thirty-one percent), "school" (sixteen percent), and "better housing / housing less expensive" (twelve percent). 
characteristics. One reason for the lack of relationship between crowded housing conditions and health outcomes in this study may be parents' subjective perceptions regarding the number of people who live in their homes. For example, crowding may not have the expected negative effect on mental health if it is by choice rather than because of financial reasons, or if it is associated with social support (Hwang et al. 1999). Quinless (2014) found that increased household size was associated with fewer chronic health conditions in Aboriginal children. Also, the current study used more than one person per room as its measure of crowding, as the measure based on the National Occupancy Standard (NOS) used by CMHC was not available on the ACS. The more stringent measure, based on the NOS, may have associations with physical and mental health that could be investigated in future research.

Lastly, one variable examining the psychological aspects of housing was examined in this study. Off-reserve First Nations children who had parents who were satisfied with their housing conditions were more likely to be in excellent or very good health, and had higher prosocial behaviour scores and fewer emotional symptoms, as well as lower conduct-problem scores. All of these associations remained after controlling for family socioeconomic factors. Other research has found similar findings, but why housing satisfaction is related to children's health outcomes is unclear. Satisfaction with housing is subjective and may be influenced by many factors, such as costs, housing availability and quality, views of neighbourhood safety, and availability and quality of play areas for children (Moloughney 2004). Kohen et al. (2015) found that housing satisfaction was associated with physical housing characteristics (less crowding and houses not in need of major repair) in Inuit children. As well, material and spatial dimensions are also related to psychological aspects of housing, as homeownership, financial worries, and crowding can all be related to a people's emotional stress levels if they feel a lack of control over these aspects of their housing (CMHC 2004). These pathways could be investigated in future research.

\section{Limitations and Conclusion}

This study is limited to the housing and health variables that were collected as part of the 2006 ACS. The 2006 ACS is a cross-sectional survey based on parent/guardian-reported data; all findings are best interpreted as correlations and not as causal effects, since they are based on reports from one time period. In addition, interactions among risk factors, as well as combined or cumulative impacts over time, could not be investigated.

Prior to this study, relatively little empirical research had examined the relationship between housing characteristics and health outcomes for First Nations children. This study provides evidence that the conditions in which young off-reserve First Nations children live, such as homeownership status, residential mobility, and parental satisfaction with housing are associated with children's physical and mental health, even after controlling for

family socioeconomic factors, area of residence, and a child's age and sex. Future research is needed to investigate further the mechanisms at play. 


\section{Bibliography}

Boyle, M.H. 2002. "Home Ownership and the Emotional and Behavioural Problems of Children and Youth." Child Development 73 (3): 883-92. doi:10.1111/14678624.00445 .

Bulkow L.R., R.J. Singleton, R.A. Karron, and L.H. Harrison. 2002. "Risk Factors for Severe Respiratory Syncytial Virus Infection among Alaska Native Children.” Pediatrics 109 (2): 210-16. doi:10.1542/peds.109.2.210.

Burton, P., L. Lethbridge, and S. Phipps. 2007. "Child Health and Parental Paid Work." Paper presented at the Canadian Employment Research Forum (CERF) conference, Halifax, May 31, 2007. Accessed March 17, 2015. http://www.cerforum.org/ conferences/200705/papers/BurtonLethbridgePhipps.pdf.

Canada Mortgage and Housing Corporation. 2002. Effects of Urban Aboriginal Residential Mobility. Ottawa: CMHC Socio-economic Series no. 114.

Canada Mortgage and Housing Corporation. 2004. Housing and Population HealthResearch Framework. Ottawa: CMHC Socio-economic Series no. 04-016.

Canada Mortgage and Housing Corporation. 2009. 2006 Census Housing Series: Issue 6Off-reserve Status Indian Households: Housing Conditions and Core Housing Need. Ottawa: CMHC Socio-economic Series no. 09-024.

Canada Mortgage and Housing Corporation. 2011a. 2006 Census Housing Series: Issue 11Off-reserve Non-Status Indian Households: Housing Conditions and Core Housing Need. Ottawa: CMHC Socio-economic Series no. 11-001.

Canada Mortgage and Housing Corporation. 2011b. 2006 Census Housing Series: Issue 13On-Reserve Housing Conditions. Ottawa: CMHC Socio-economic Series no. 11-007.

Dong, M., R.F. Anda, V.J. Felitti, D.F. Williamson, S.R. Dube, D.W. Brown, and W.H. Giles. 2005. "Childhood Residential Mobility and Multiple Health Risks During Adolescence and Adulthood." Arch Pediatr Adolesc Med 159: 1104-10. doi:10.1001/ archpedi.159.12.1104.

Evans, G.W. 2006. “Child Development and the Physical Environment.” Annual Review of Psychology 57: 401-24. doi:10.1146/annurev.psych.57.102904.190057.

Findlay, L. and T. Janz. 2012. "Health of First Nations Children Living Off Reserve and Métis Children Younger than Age 6." Health Reports 23 (1). Ottawa: Statistics Canada Catalogue no. 82-003-X. 
Gao, Z., B.H. Rowe, C. Majaesic, C. O’Hara, and A. Senthilselva. 2008. "Prevalence of Asthma and Risk Factors for Asthma-like Symptoms in Aboriginal and NonAboriginal Children in the Northern Territories of Canada." Can Respir J 15 (3): 139-45.

Gionet, L. and S. Roshanafshar. 2013. "Select Health Indicators of First Nations People Living Off Reserve, Métis and Inuit." Health at a Glance. Ottawa: Statistics Canada Catalogue no. 82-624-X.

Goodman, R. 1997. “The Strengths and Difficulties Questionnaire: A Research Note.” Journal of Child Psychology and Psychiatry 38 (5): 581-86. doi:10.1111/j.1469-7610.1997. tb01545.x.

Goodman, R. 2001. "Psychometric Properties of the Strengths and Difficulties Questionnaire." Journal of the American Academy of Child and Adolescent Psychiatry 40: 1337-45. doi:10.1097/00004583-200111000-00015.

Haurin, D.R., T.L. Parcel, and R.J. Haurin. 2002. "Does Homeownership Affect Child Outcomes?" Real Estate Economics 30 (4): 635-66. doi:10.1111/1540-6229.t01-200053.

Hofhuis, W., J.C. de Jongste, and P.J. Merkus. 2003. "Adverse Health Effects of Prenatal and Postnatal Tobacco Smoke Exposure on Children." Arch Dis Child 88: 1086-90. doi:10.1136/adc.88.12.1086.

Hofferth, S.L., and J.F. Sandberg. 2001. "How American Children Spend Their Time.” Journal of Marriage and the Family 63: 295-308. doi:10.1111/j.1741-3737.2001.00295.x.

Hwang, S., E. Fuller-Thomson, J.D. Hulchanski, T. Bryant, Y. Habib, and W. Regoeczi. 1999. Housing and Population Health: A Review of the Literature. Ottawa: Canada Mortgage and Housing Corporation.

Hwang, S.-H., J.H. Hwang, J.S. Moon, and D.-H. Lee. 2012. "Environmental Tobacco Smoke and Children's Health.” Korean J Pediatr 55 (2): 35-41. http://dx.doi.org/10.3345/ kjp.2012.55.2.35.

Jaakkola, J.J.K., and M. Gissler. 2004. "Maternal Smoking in Pregnancy, Fetal Development and Childhood Asthma." Am J Public Health 94 (1): 136-40. doi:10.2105/ ajph.94.1.136. 
Jelleyman, T. and N. Spencer. 2008. "Residential Mobility in Childhood and Health Outcomes: A Systematic Review." J Epidemiol Community Health 62 (7): 584-92. doi:10.1136/jech.2007.060103.

Kohen, D.E., E. Bougie, A. Guevremont. 2015. "Housing and Health among Inuit Children.” Health Reports 26 (11): 3-9.

Kohen, D.E., T. Leventhal, V.S. Dahinten, and C.N. McIntosh. 2008. "Neighborhood Disadvantage: Pathways of Effects for Young Children." Child Development 79 (1): 156-69. doi:10.1111/j.1467-8624.2007.01117.x.

Kovesi T., N.L. Gilbert, C. Stocco, D. Fugler, R.E. Dales, M. Guay, and J.D. Miller. 2007. "Indoor Air Quality and the Risk of Lower Respiratory Tract Infections in Young Canadian Inuit Children." Canadian Medical Association Journal 177 (2): 155-60. doi:10.1503/cmaj.061574.

Larcombe, L., P. Nickerson, M. Singer, R. Robson, J. Dantouze, L. McKay, and P. Orr. 2011. "Housing Conditions in Two Canadian First Nations Communities." International Journal of Circumpolar Health 70 (2): 141-53. doi:10.3402/ijch.v70i2.17806.

MacMillan, H.L., E. Jamieson, C. Walsh, M. Boyle, A. Crawford, and A. MacMillan. 2010. "The Health of Canada's Aboriginal Children: Results from the First Nations and Inuit Regional Health Survey." International Journal of Circumpolar Health 69 (2): 158-67. doi:http://dx.doi.org/10.3402/ijch.v69i2.17439.

Moloughney, B. 2004. Housing and Population Health: The State of Current Research Knowledge. Ottawa: Canadian Institute for Health Information.

Oliver, L., L. Findlay, C. McIntosh, and D. Kohen. 2009. Evaluation of the Strengths and Difficulties Questionnaire. Ottawa: Statistics Canada Catalogue no. 89-634-X no. 008 .

Oliver, L.N. and D.E. Kohen. 2012. "Unintentional Injury Hospitalizations among Children and Youth in Areas with a High Percentage of Aboriginal Identity Residents: 2001/2002 to 2005/2006." Health Reports 23 (3). Ottawa: Statistics Canada Catalogue no. 82-003-XPE.

Power, C. and C. Hertzman. 1997. "Social and Biological Pathways Linking Early Life and Adult Disease." British Medical Bulletin 53 (1), 210-21. doi:10.1093/oxfordjournals. bmb.a011601. 
Quinless, J. 2014. "Family Matters: Household Size in Relation to the Well-Being of Aboriginal School-Aged Children Living Off-Reserve." Aboriginal Policy Studies 3 (1\&2): 5-28. doi:10.5663/aps.v3i1-2.21701.

Reading, J. 2009. The Crisis of Chronic Disease among Aboriginal Peoples: A Challenge for Public Health, Population Health and Social Policy. Victoria, British Columbia: University of Victoria, Centre for Aboriginal Health Research.

Statistics Canada. 2008. Aboriginal Peoples in Canada in 2006: Inuit, Métis and First Nations, 2006 Census. Ottawa: Statistics Canada Catalogue no. 97-558-XIE.

Stevens, J.P. 2002. Applied Multivariate Statistics for the Social Sciences. Mahwah, NJ: LEA. $4^{\text {th }}$ edition.

Tabachnick, B.G. and L.S. Fidell. 2001. Using Multivariate Statistics. Boston, MA: Allyn and Bacon. $4^{\text {th }}$ edition.

UNICEF Canada. 2009. Aboriginal Children's Health: Leaving No Child Behind. Toronto: UNICEF Canada.

Weitzman, M., S. Gortmaker, and A. Sobol. 1992. "Maternal Smoking and Behavior Problems of Children.” Pediatrics 90 (3): 342-49.

World Health Organization. 2011. Environmental Burden of Disease Associated with Inadequate Housing. A Method Guide in the Quantification of Health Effects of Selected Housing Risks in the WHO European Region. Copenhagen: World Health Organization. 


\section{Appendix}

TABLE A: Multicollinearity diagnostics (tolerance and variance inflation), housing conditions and selected characteristics, First Nations children living off reserve, ages two to five, Canada, ACS 2006

\begin{tabular}{|l|l|l|}
\hline Variable & Tolerance & Variance Inflation \\
\hline Intercept & $\cdot$ & 0 \\
\hline Crowding & 0.94 & 1.07 \\
\hline Dwelling in need of major repair & 0.94 & 1.06 \\
\hline Unaffordable housing & 0.82 & 1.23 \\
\hline Homeownership & 0.69 & 1.45 \\
\hline One or more moves per year of age & 0.96 & 1.04 \\
\hline Parental satisfaction with housing conditions & 0.89 & 1.12 \\
\hline Regular smoker in the house & 0.95 & 1.05 \\
\hline Household income adjusted & 0.67 & 1.49 \\
\hline Parents' highest level of education & 0.90 & 1.12 \\
\hline Single-parent family & 0.85 & 1.17 \\
\hline Area of residence & 0.91 & 1.09 \\
\hline
\end{tabular}

Source: 2006 Aboriginal Children’s Survey 